\title{
Hepatocyte Growth Factor Exerts Multiple Biological Functions on Bovine Mammary Epithelial Cells
}

\author{
P. Accornero, ${ }^{1}$ E. Martignani, E. Macchi, and M. Baratta \\ Department of Veterinary Morphophysiology, University of Torino, Via Leonardo da Vinci 44, 10095, Grugliasco (TO), Italy
}

\begin{abstract}
The met proto-oncogene product Met is a member of the family of tyrosine kinase growth factor receptors, and hepatocyte growth factor/scatter factor (HGF/SF) has been identified as its only ligand. Bovine Met and $\mathrm{HGF} / \mathrm{SF}$ have been recently cloned and their expression has been characterized in the mammary gland, but no data regarding the biological effects of this ligand/receptor couple in bovine mammary cells are yet available. We examined the role of $\mathrm{HGF} / \mathrm{SF}$ and its receptor in a bovine mammary epithelial cell line (BME-UV). Expression of Met at the mRNA level in BME-UV mammary epithelial cells evaluated by real-time PCR was similar to the expression in MDCK cells, a widely used model for Met biology. Met expression in BME-UV at the protein level was confirmed by western blot. The analysis of some signal transductional pathways downstream from the Met receptor revealed that $\mathrm{HGF} / \mathrm{SF}$ addition to BME-UV cells induced activation of the extracellular signal-regulated kinase $1 / 2$ proliferative pathway and the Akt antiapoptotic pathway. The BMEUV cells treated with HGF responded with increased proliferation, cell scatter, and motility. Met activation by HGF induced degradation of the extracellular matrix and migration through matrigel coated transwells. Moreover, BME-UV cells included in a 3-dimensional matrix of collagen and treated with HGF developed tubular structures, reminiscent of the mammary gland ducts. These data indicate that HGF and Met might be important regulators of mammary gland growth, morphogenesis, and development in the bovine.
\end{abstract}

Key words: Met, hepatocyte growth factor, bovine mammary gland, tubulogenesis

\section{INTRODUCTION}

Hepatocyte growth factor/scatter factor (HGF/SF) was identified as a potent inducer of motility in different

Received March 8, 2007.

Accepted May 16, 2007.

${ }^{1}$ Corresponding author: paolo.accornero@unito.it cell types (Stoker et al., 1987) and a mitogenic factor for hepatocytes in primary culture (Nakamura et al., 1989) using 2 independent experimental approaches. Later works established that these 2 factors are the same molecule (Gherardi and Stoker, 1990). The receptor for HGF, Met, was identified by means of the activated oncogene tpr-met (Cooper et al., 1984). Met is a tyrosine kinase composed of a disulfide-linked heterodimer, which results from cleavage of a $190-\mathrm{kD}$ a precursor in a mature extracellular $\alpha$ chain and a longer transmembrane $\beta$ chain (Bottaro et al., 1991). Met expression is generally restricted to cells of epithelial origin, whereas HGF is secreted by fibroblasts and stromal cells in the surrounding mesenchyme. This paracrine signaling system is important in regulating the interaction between epithelial and mesenchymal cells. Binding of HGF to its receptor induces receptor dimerization and activates many signal transductional pathways that drive multiple biological responses such as proliferation, inhibition of apoptosis, motility, invasion of the extracellular matrix, and activation of angiogenesis (Bussolino et al., 1992; Brinkmann et al., 1995; Bardelli et al., 1996; Medico et al., 1996; Rosario and Birchmeier, 2003).

The bovine mammary gland is an organ in which numerous remodeling events follow each other during the development and the reproductive cycle. At birth only a rudimentary duct network is present. At 2 to 3 mo of age numerous ducts develop as compact, highly arborescent structures within loose connective tissue. Ductal elongation is accomplished through the coordinated growth, branching and extension of terminal ductal units (TDU), and growth of the loose connective tissue that surrounds the TDU as it invades the mammary fat pad. After puberty and during pregnancy the bovine mammary gland undergoes an extensive development: epithelial growth gives rise to more extensive ductules branching and to alveolar structures by proliferation followed by terminal differentiation of cells within the distal termini of ductules (Ellis and Capuco, 2002).

Branching morphogenesis and lobulo-alveolar differentiation of the mammary gland are regulated by a 
complex interplay of systemic hormonal signals and local factors. In these processes mesenchymal-epithelial as well as epithelial-mesenchymal interactions involving the cells of the fat pad and the ducts and alveoli play an important role. It has been reported that HGF and Met are expressed and temporally regulated during mammary development and differentiation (Niranjan et al., 1995; Yang et al., 1995) and that HGF acts in vitro as a unique morphogen, inducing kidney and mammary derived cells to form branching ducts when included in a 3-dimensional matrix of collagen (Montesano et al., 1991; Soriano et al., 1995). In vivo Met signaling has been implicated in stimulating tubulogenesis during the formation of several organs, including the mammary gland (Birchmeier and Gherardi, 1998).

Recently bovine HGF and Met have been analyzed for their expression in the mammary gland (Yamaji et al., 2006), but no data regarding their biological roles are yet available. The objective of this study was to characterize some biological and biochemical properties elicited by HGF on BME-UV bovine mammary epithelial cells.

\section{MATERIALS AND METHODS}

\section{Materials, Cells, and Antibodies}

All reagents, unless specified, were from Sigma-Aldrich (St. Louis, MO); recombinant $\mathrm{HGF}$ and epidermal growth factor (EGF) were from Immunotools (Friesoythe, Germany); NucleoSpin RNA II were from Macherey-Nagel (Duren, Germany); BioRad iScript cDNA kit, iQ SYBR Green Supermix and DC Protein Assay were from BioRad Laboratories (Hercules, CA); Hybond-ECL nitrocellulose membrane and Hyperfilm ECL were from GE Healthcare BioSciences (Piscataway, NJ); Super Signal West Pico Chemiluminescent Substrate was from Pierce (Rockford, IL); WST-1 cell proliferation reagent was from Roche (Mannheim, Germany); transwell polycarbonate membranes were from Corning-Costar (Corning, NY); Matrigel Basement Membrane Matrix was from BD Biosciences (Bedford, MA); microplate microspectrophotometer (model Biorad 680) was from BioRad Laboratories; the programmable real-time thermal cycler (model Mini-Opticon) was from MJ Research Inc. (Watertown, MA).

The BME-UV bovine mammary epithelial cell line was kindly provided by I. Politis (University of Vermont, Burlington). The BME-UV cells were established from bovine primary epithelial cells and express functional markers such as microvilli and desmosomes and biochemical markers of mammary epithelial cells such as a repertoire of cytokeratins (Zavizion et al., 1996). The BME-UV cells were maintained in Dulbecco's modified Eagle medium supplemented with $10 \%$ fetal bovine serum (FBS, Euroclone, Pero, Italy) and $10 \mu \mathrm{g} / \mathrm{mL}$ of insulin at $37^{\circ} \mathrm{C}$ in a $5 \% \mathrm{CO}_{2}$-water-saturated atmosphere, and cells were routinely passaged every 2 to 3 d by washing with PBS followed by trypsinization.

The MDCK kidney epithelial cell line was kindly provided by C. Ponzetto (University of Torino, Italy). The MDCK cells were maintained in Dulbecco's modified Eagle medium supplemented with $10 \%$ fetal calf serum and passaged every 2 to $3 \mathrm{~d}$.

Anti-Met mouse monoclonal antibody was from Zymed (South San Francisco, CA); anti-ErbB-1 rabbit polyclonal antibody was from Santa Cruz Biotechnology (Santa Cruz, CA); anti $\alpha$-tubulin and anti-phospho-extracellular signal-regulated kinases $1 / 2$ (Erk) mouse monoclonal antibodies were from Sigma-Aldrich (St. Louis, MO); anti-Erk 1/2 rabbit polyclonal, anti-phosphoAkt mouse monoclonal and anti-Akt rabbit polyclonal antibodies were from Cell Signaling Technologies (Danvers, MA).

\section{Preparation of mRNA and Real-Time PCR}

Real-time PCR assays were performed as described in Hecht et al. (2005). Briefly, BME-UV and MDCK cells were plated in 6-well plates and cultured in $10 \%$ FBS until they reached $90 \%$ confluence. Total RNA was extracted with NucleoSpin RNA II kit following the manufacturer's recommended protocol. One microgram of total RNA extracted from BME-UV and MDCK cells was reverse transcribed with iScript cDNA kit following the manufacturer's instructions. Diluted cDNA (1:5 and 1:50) were used for real-time PCR amplification using iQ SYBR Green Supermix. Because of the high homology in the sequence of bovine and canine Met mRNA, primers used to amplify bovine and canine Met cDNAs had the same sequence (and thus the same amplification efficiency). Primers for Met were forward 5'-CGC TAT GAT GCA AGA GTA CAC A-3', reverse 5'-TTA GGA AAC TGG TCT TCT GGA-3'; primers for ribosomal 18S were forward 5'-CGT TTG TGT GGG GAG TGA ATG GTG-3', reverse 5'-GCG TGG GGG TTG GCG GAA AGA GAA-3'. Real-time PCR parameters were: cycle $1,95^{\circ} \mathrm{C}$ for $90 \mathrm{~s}$; cycle $2,95^{\circ} \mathrm{C}$ for $60 \mathrm{~s}, 60^{\circ} \mathrm{C}$ for $10 \mathrm{~s}$ for 40 cycles. The $2^{-\Delta \Delta \mathrm{C}_{\mathrm{T}}}$ method was used to analyze the data as described by Livak and Schmittgen (2001).

\section{Western Blot Analysis}

Western blot analysis was performed as described in Maritano et al. (2000). Briefly, cells were lysed and 20 $\mu \mathrm{g}$ of total protein lysate was resolved in 10\% SDSPAGE gels. Proteins were transferred to Hybond-C Extra nitrocellulose membranes, blocked with Tris-buffered saline containing $10 \%$ BSA and then incubated 
overnight at $4{ }^{\circ} \mathrm{C}$ with the appropriate primary antibodies. After extensive wash the membranes were incubated for $1 \mathrm{~h}$ with horseradish peroxidase conjugated secondary antibodies. The membrane were washed again and incubated with Super Signal West Pico enhanced chemiluminescence peroxidase substrate. The proteins were visualized by briefly exposing the membrane to an autoradiographic Hyperfilm ECL.

\section{Cell Proliferation Assay and Statistical Analysis}

The BME-UV cells were seeded in 96-well plates at a density of $3 \times 10^{3}$ per well and allowed to grow. After $24 \mathrm{~h}$ the medium was removed and replaced with medium containing the indicated cytokines. Cell proliferation was evaluated after $48 \mathrm{~h}$ using the WST-1 assay following the manufacturer's instructions. Briefly, the intensity of the colored compound formed (formazan dye) was quantified with an ELISA microplate reader. When WST-1 reagent was added the wells were subjected to further incubation for a period of $60 \mathrm{~min}$ to facilitate the reaction between mitochondrial dehydrogenase released from viable cells and tetrazolium salt of WST-1 reagent. The absorbance was measured at $450 \mathrm{~nm}$, with the reference at $620 \mathrm{~nm}$. Cell viability of the untreated cells was set to $100 \%$. Each experiment was repeated 3 times independently, and in each experiment each treatment was performed with 6 replicate culture wells. Experimental data are presented as mean \pm SD. Statistical differences between treatments and interactions were calculated with multifactorial ANOVA using the Statgraphics package (STSC Inc., Rockville, MD). When significant differences were found, means were compared by Scheffè $F$-test.

\section{Scatter Assay}

The BME-UV cells were seeded in 96-well plates at a density of $5 \times 10^{3}$ cells/well and cultured until they formed tightly packed colonies. After $24 \mathrm{~h}$ the medium was replaced and cells were stimulated overnight with $10 \mathrm{ng} / \mathrm{mL}$ of HGF or EGF. After $16 \mathrm{~h}$, cells were fixed with glutaraldehyde $11 \%$ in PBS for $10 \mathrm{~min}$, colored with crystal violet, and photographed.

\section{In Vitro Invasion Assay}

Invasion assay $(6.5 \mathrm{~mm}$ diameter, $8 \mu \mathrm{m}$ pore size transwells) was performed as described (Taulli et al., 2005). Briefly, $3 \times 10^{4} \mathrm{BME}-\mathrm{UV}$ cells were seeded onto the upper well of transwells coated with $25 \mu \mathrm{g}$ of Matrigel. After $48 \mathrm{~h}$ the noninvasive cells on the upper surface of the membrane were removed with a cotton swab. Cells that invaded were fixed with $11 \%$ glutaraldehyde, stained with crystal violet, and photographed. For quantification, the membranes were detached and solubilized in $10 \%$ acetic acid water solution, and the intensity of the colored solution was quantified by spectrophotometrical analysis at $595 \mathrm{~nm}$. The intensity of the untreated control transwell was set to $100 \%$.

\section{Tubulogenesis Assay}

The tubulogenesis assay was performed as described (Montesano et al., 1991). Briefly, $3 \times 10^{3}$ BME-UV cells were embedded in 3-dimensional collagen gels. After the collagen solution had gelled, $1 \mathrm{~mL}$ of complete medium was added to each well with the indicated agents. Media were changed every 2 to $3 \mathrm{~d}$, the cultures incubated at $37^{\circ} \mathrm{C}$ for $7 \mathrm{~d}$ and photographed with a Leica DFC350FX digital camera (Leica, Nussloch, Germany). Frames taken from multiple focuses were recomposed on a single picture using an extended depth of field software, Combine Z5 (freeware software from Alan Hadley, http://www.hadleyweb.pwp.blueyonder.co.uk/ CZ5/combinez5.htm; accessed June 30, 2007).

\section{RESULTS}

\section{Expression of Met Receptor mRNA and Protein in BME-UV Bovine Mammary Epithelial Cells}

To test the biological effects of HGF on BME-UV mammary cells, we first verified, at the mRNA and at the protein level, if this cell line expressed Met. To evaluate Met expression we used the MDCK cell line, which is a widely accepted model for Met biology, as a positive control. Met expression in BME-UV and MDCK cell lines was measured by real-time PCR and normalized against 18S ribosomal RNA. Met mRNA levels in BME-UV and MDCK cell lines were comparable (Figure $1 \mathrm{~A})$.

Met expression at the protein level (Figure 1B) agreed well with the data obtained by real-time PCR. A lysate obtained from mouse liver was used as a positive control. The Met 190-kDa precursor and the mature 140$\mathrm{kDa}$ Met receptor were visible. Tubulin was used to normalize the expression for BME-UV and MDCK cell lines. Because the BME-UV cell line is of epithelial origin, we also verified if it expressed the EGF receptor (ErbB-1) to use EGF as a possible positive control in the subsequent biochemical and biological assays. The 170-kDa ErbB-1 receptor was clearly detected in BMEUV and in MDCK cells.

\section{HGF and EGF Activate the Erk 1/2 and the Akt Pathways in BME-UV Cells}

The best-studied pathways activated downstream of the Met receptor are the MEK-dependent phosphoryla- 


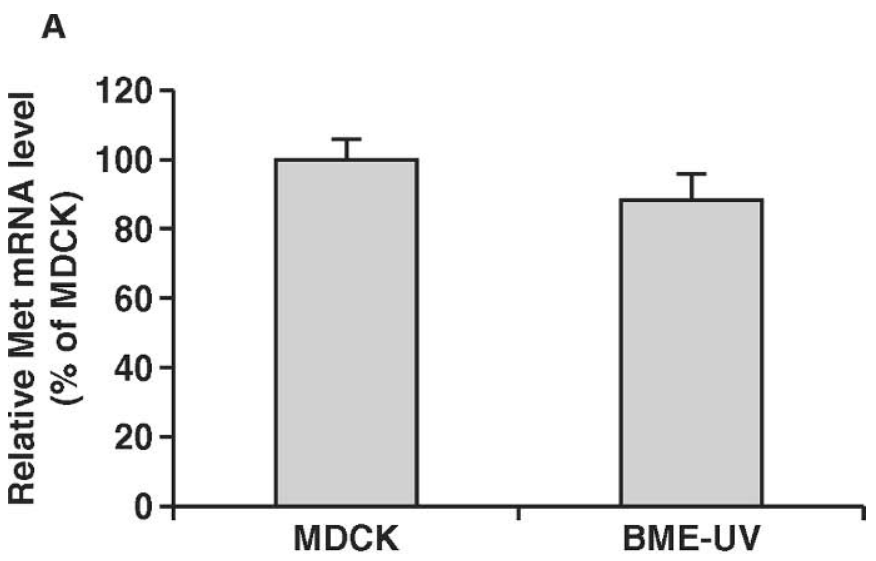

B

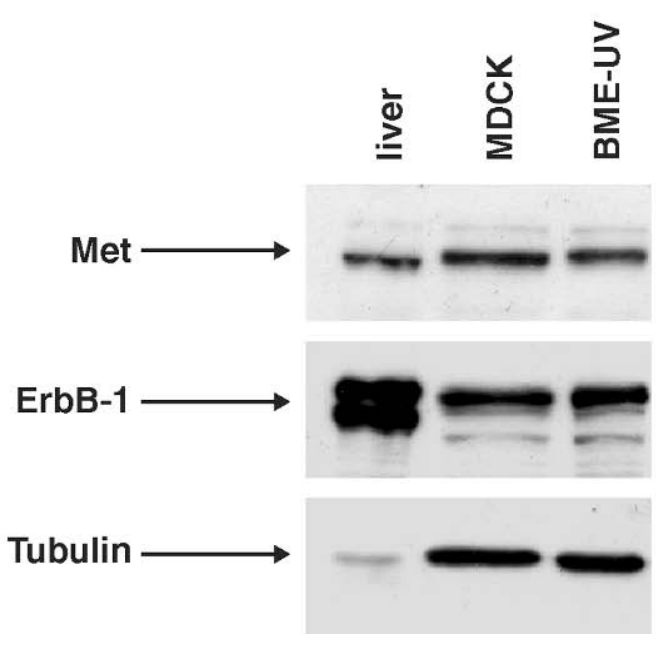

Figure 1. Relative MDCK and bovine mammary epithelial cell line (BME-UV) mRNA (A) and protein (B) levels determined by realtime PCR and western blot analysis. Total RNA and proteins were isolated from subconfluent cells. (A) Met mRNA levels were calculated using $18 \mathrm{~S}$ ribosomal RNA as a reference gene. The MDCK Met mRNA level was set to $100 \%$. Data are the average of triplicate samples from individual experiments. (B) Met protein levels were evaluated by Western blot analysis. The $190-\mathrm{kDa}$ Met precursor and $140-\mathrm{kDa}$ mature Met forms are visible. Mouse liver (left lane) was used as a positive control for Met and ErbB-1. Tubulin was used as a loading control for MDCK and BME-UV cells. Western blots were repeated 3 times with equivalent results.

tion of the MAP kinases Erk1 and Erk2 and the PI3Kdependent phosphorylation of PKB/Akt. We examined whether HGF could activate these 2 pathways in the BME-UV cell line. We used EGF as a positive control for the activation of Erk and Akt because BME-UV cells express the ErbB-1 receptor, and it is widely accepted that this receptor activates both pathways. Subconfluent BME-UV cells were serum starved for $24 \mathrm{~h}$ and then stimulated for 10,30 , and 60 min with $10 \mathrm{ng} / \mathrm{mL}$ HGF or EGF (or left unstimulated = untreated control).

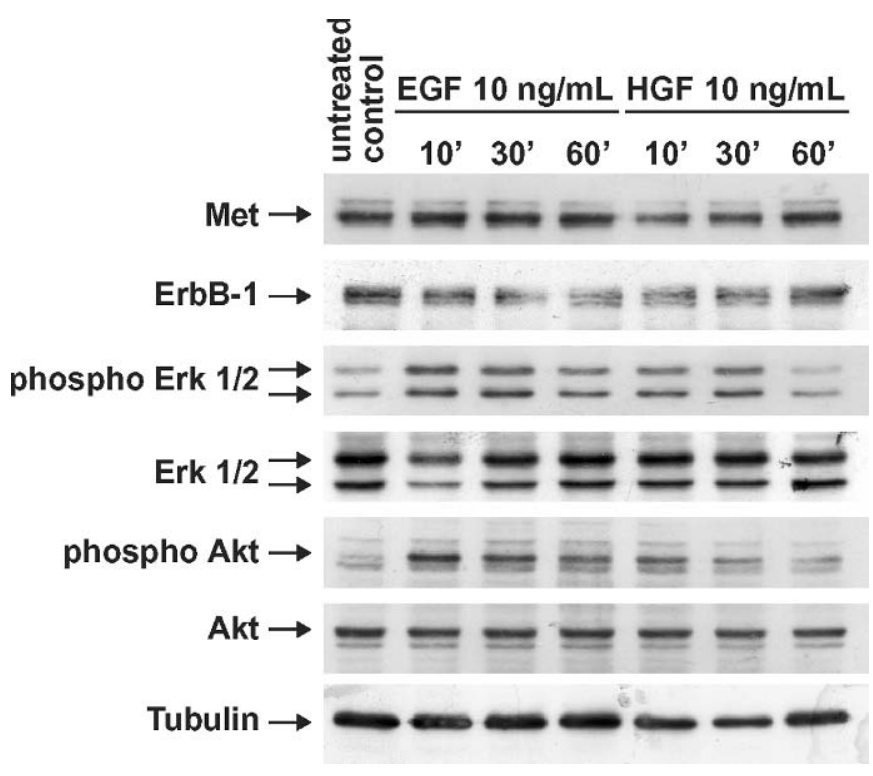

Figure 2. Effects of epidermal growth factor (EGF) and hepatocyte growth factor (HGF) on Erk $1 / 2$ and Akt pathways activation in bovine mammary epithelial (BME-UV) cells. Subconfluent BME-UV mammary cells were treated with $10 \mathrm{ng} / \mathrm{mL}$ of EGF or HGF. The EGF was used as a positive control for phosphorylation of Erk $1 / 2$ and Akt. Total Erk $1 / 2$, Akt, and Tubulin were used as loading controls. Western blots were repeated 3 times with equivalent results.

Cells were lysed, and equal amounts of total protein were subjected to Western blotting (Figure 2). Both HGF and EGF activated Erk1 and Erk2 MAP kinases and the Akt protein kinase. In HGF-treated cells, the phosphorylation intensity of all effectors returned to a basal level after $60 \mathrm{~min}$, whereas EGF activation persisted for a longer time.

\section{HGF Induces Proliferation of BME-UV Bovine Mammary Cells}

Hepatocyte growth factor has been identified as a mitogenic factor for hepatocytes and was later found to cause proliferation in other cell lines. We examined if HGF exerted a mitogenic stimulus on BME-UV cells. Cells were cultured for $48 \mathrm{~h}$ in proliferation medium without (control) or with $10 \mathrm{ng} / \mathrm{mL}$ of EGF or HGF. First, we tested different concentrations of HGF in a proliferation curve and found $10 \mathrm{ng} / \mathrm{mL}$ to be the most effective. The HGF strongly affected cell proliferation (142\%; Figure 3; $P<0.05$ ), whereas EGF could induce proliferation only to a small degree (116\%) when compared with the untreated control. Similar results were obtained when cells were cultured in low serum conditions (1\% FBS). 


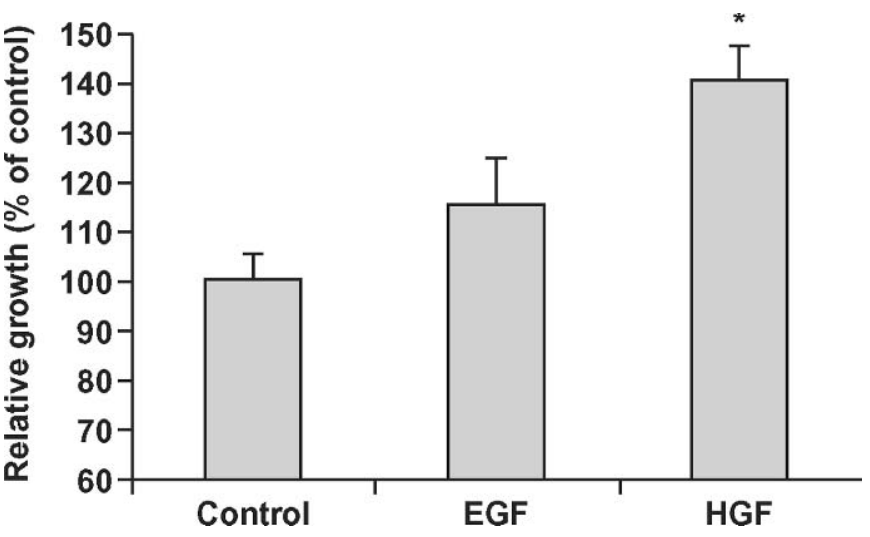

Figure 3. Effects of epidermal growth factor (EGF) or hepatocyte growth factor (HGF) on bovine mammary epithelial cell line (BMEUV) proliferation. Each bar shows quantification, in percentage relative to the untreated control. All data points in individual assays are the average obtained from six replicate culture wells. Data from 3 separate assays were statistically pooled and analyzed to yield the values shown in the graph and to test significance. Bars marked with an asterisk are significantly different $(* P<0.05)$.

\section{HGF Induces Cellular Motility and Dispersion of Bovine BME-UV Mammary Cells}

One of the most striking biological properties of Met is to induce cellular motility and dispersion (phenomenon defined as scatter). We tested whether HGF promoted scatter in BME-UV cells. At 24 to $48 \mathrm{~h}$ after plating, BME-UV bovine mammary cells form tightly packed colonies with well-defined boundaries. Cells were then treated with HGF, EGF, or untreated (control). After $16 \mathrm{~h}$ controls exhibited no change in the phenotype of the cells, whereas HGF treatment promoted cell motility. The colonies underwent complete colony spreading (Figure 4). In EGF-treated wells, colonies started to enlarge and cells to disperse, a phenomenon known as cell spreading, but scatter was never observed even with longer incubation times.

\section{HGF, But Not EGF, Induces Degradation of the Extracellular Matrix and Migration in BME-UV Mammary Cells}

We assessed whether BME-UV cells could promote "invasion" after incubation with HGF. Whereas controls did not invade, HGF-treated cells dissolved the matrix and passed through the pores of the transwells. The EGF had very little effect on BME-UV cell invasion (Figure 5A). Quantification of cells that passed through the transwells confirmed that HGF was able to induce invasion to a very high degree (Figure 5B).
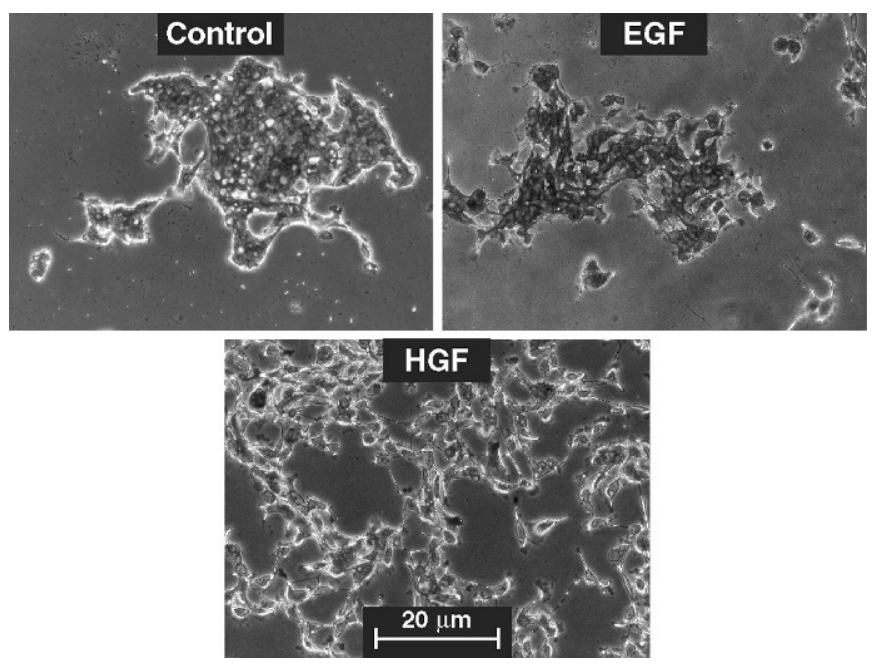

Figure 4. Effects of epidermal growth factor (EGF) and hepatocyte growth factor (HGF) on bovine mammary epithelial cell line (BMEUV) scatter. The BME-UV mammary cells were incubated in proliferating medium without (control) or with the indicated cytokines (10 $\mathrm{ng} / \mathrm{mL}$ ) for $16 \mathrm{~h}$. The scatter assay was repeated 3 times with similar results. Magnification: $\times 200$.
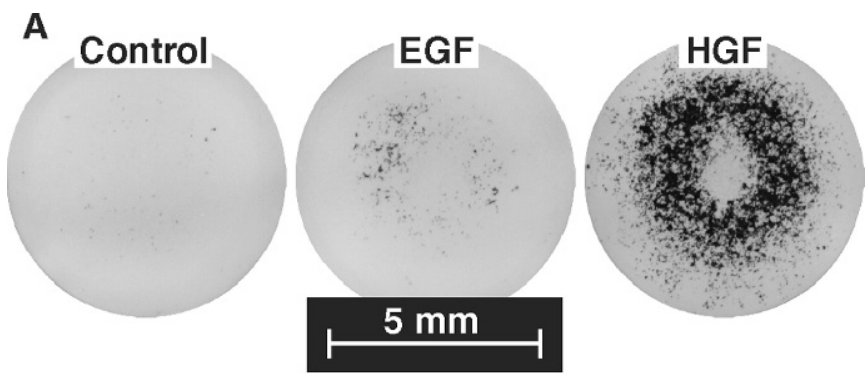

B

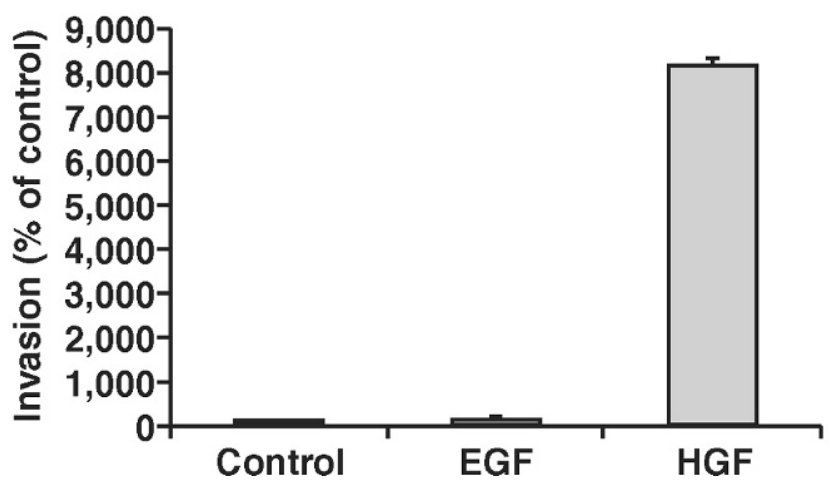

Figure 5. Effects of epidermal growth factor (EGF) and hepatocyte growth factor (HGF) on bovine mammary epithelial cell line (BMEUV) matrix degradation and cell invasion. (A) Scanner pictures of BME-UV cells that migrated through transwells after induction without (control) or with the indicated cytokines $(10 \mathrm{ng} / \mathrm{mL}$ ) for $48 \mathrm{~h}$. (B) Spectrophotometric quantification of the transwells in A. The values are expressed in percentage relative to the untreated control. The transwells assay was repeated 3 times with similar results. Error bars are the standard error of the 3 independent experiments. 


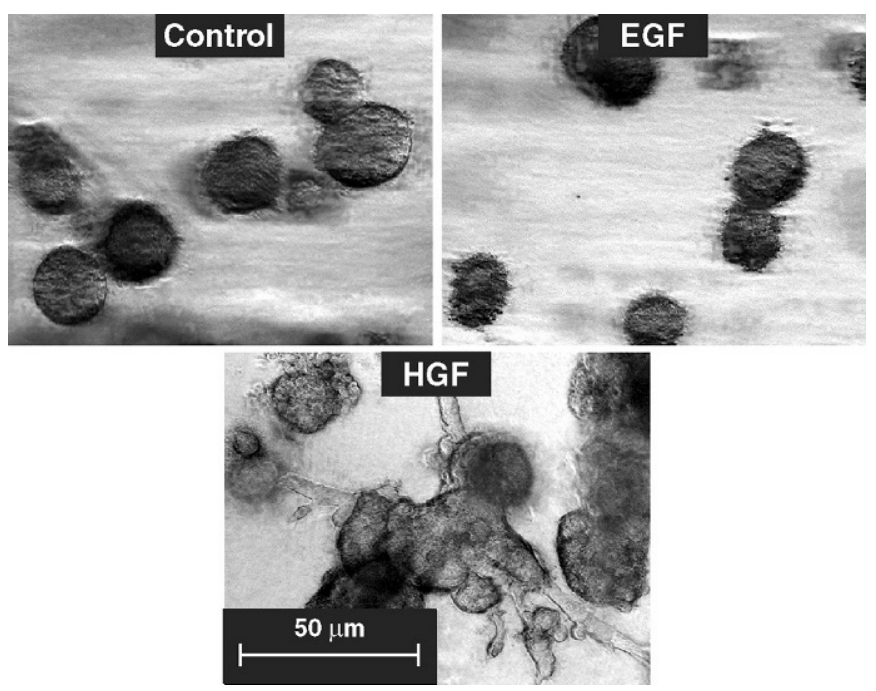

Figure 6. Effect of epidermal growth factor (EGF) and hepatocyte growth factor (HGF) on bovine mammary epithelial cell line (BMEUV) tubulogenesis. The BME-UV cells were included in a 3-dimensional matrix of collagen as described in section 2 . The indicated cytokines were added to the proliferating medium and changed every $2 \mathrm{~d}$. Pictures were taken after $7 \mathrm{~d}$ of culture. Magnification: $\times 50$.

\section{HGF, But Not EGF, Induces Tubule Formation in BME-UV Mammary Cells}

Hepatocyte growth factor was identified as necessary and sufficient to stimulate epithelial cells to form tubule-like extensions when seeded in 3-dimensional matrices (a phenomenon called branching morphogenesis; Brinkmann et al., 1995). We assessed whether BMEUV cells grown in a 3-dimensional collagen matrix were able to develop tubules if left unstimulated (control) or when stimulated with HGF or EGF (Figure 6). In collagen, control and EGF-treated BME-UV cells formed only tightly packed spheres (mammosphere) with no extensions. When HGF was added to the culture medium, some mammospheres extended processes and formed cell chains that lengthened and thickened. Only a limited number of BME-UV cells included in the collagen still retained the capacity to form tubules when stimulated with HGF ( 3 to 5 tubules per well with $3 \times$ $10^{3}$ cells).

\section{DISCUSSION}

Tubulogenesis and ramification are complex morphogenetic processes that are active in the developing mammary gland and require an efficient coordination between cellular proliferation, polarity, and movement. Bovine tyrosine kinase receptor Met and its ligand HGF have been recently cloned and their expression in the developing mammary gland has been analyzed, but the biological properties of HGF on bovine mammary epithelial cell lines have not been illustrated. We used the BME-UV bovine mammary cell line as a model to investigate the different functional properties of HGF and its receptor. This cell line was established from bovine primary epithelial cells and express biochemical markers of mammary epithelial cells such as cytokeratins (Zavizion et al., 1996).

We first demonstrated that Met is expressed in this cell line at the mRNA level by real time PCR and at the protein level by western blot. We used canine MDCK cell line and mouse liver as internal positive controls for Met expression because both have been widely used to investigate the different roles of Met in vitro and in vivo (Rosario and Birchmeier, 2003). Western blot and real-time PCR analysis showed that BME-UV have levels of Met expression comparable with MDCK.

Ligation of active HGF to Met results in dimerization of the Met receptor and transautophosphorylation. These phosphorylation events lead to full receptor activation and allow the recruitment of numerous signaling mediators such as phosphoinositide 3-kinase (PI3K) and Src tyrosine kinase, as well as several adaptor proteins such as Grb2 (which activates the Erk pathway), Gab1, Shc, and c-Cbl.

The HGF-induced activation of Met in BME-UV cells resulted in MEK-dependent phosphorylation of the MAP kinases Erk1 and Erk2. Activated Erk $12 / 2$, which regulate ETS/AP1 transcription factors and adhesion molecules, have been directly linked to cell proliferation and motility (Ridley et al., 1995; Wasylyk et al., 1998). Furthermore, upon HGF stimulation of BME-UV cells, we observed phosphorylation of PKB/Akt. By direct phosphorylation, PKB can inhibit BAD and caspase-9 and activate $\mathrm{IKK} \alpha$ resulting in activation of $\mathrm{NF} \kappa \mathrm{B}$. All these events contribute to Akt antiapoptotic function (Vivanco and Sawyers, 2002). The PI3K pathway is also important for the disassembly of adherens junctions, cell spreading, and motility (Khwaja et al., 1998; Potempa and Ridley, 1998). Epidermal growth factor also activated the Erk/MAPK and the PI3K-Akt/PKB pathways. The EGF-induced phosphorylation of these 2 pathways persisted for a longer time (more than $1 \mathrm{~h}$ ) when compared with HGF.

Given that the activation of Erk kinases has been linked with proliferation, we verified whether HGF could enhance proliferation in BME-UV cells. The HGFinduced cell proliferation has already been demonstrated in human and mouse mammary cells (Niranjan et al., 1995; Yant et al., 1998) but, to our knowledge, never demonstrated in the bovine. In BME-UV cells, HGF promoted proliferation and the increase in prolif- 
eration, relative to the untreated control, was greater than EGF.

In the late 1980s, Stoker et al. (1987) showed that MDCK cells—a polarized epithelial cell line-displayed a phenomenon defined as scatter in which cells acquire a fibroblastic migratory phenotype when incubated in a medium containing HGF. Because scatter is a necessary event that occurs before several morphogenic processes like tubulogenesis in the mammary gland, it was interesting to observe that HGF was the only cytokine able to fully dissociate BME-UV cells and induce motility. Epidermal growth factor provoked cell spreading but could not induce complete cell dissociation in the colonies.

During embryogenesis, invasive growth is involved in complex developmental events including morphogenesis of epithelia, angiogenesis, nerve sprouting, and myoblast migration. This feature is also of great importance in the developing mammary gland. In this context, cells that colonize the gland and create the new tubular structures of this organ must destroy the surrounding extracellular matrix, proliferate, and move to create new tissue (Kadono et al., 1998). Invading cells induce a constant and dynamic remodeling of integrinmediated adhesive contacts with the extracellular cell matrix, which provides a mechanical support for cell migration and prevents the induction of apoptosis. Hepatocyte growth factor and Met have been described as strong inducers of invasion, but their role in nontumorigenic mammary cell lines have never been explored. The BME-UV cell line stimulated with HGF responded with an increase in the ability to degrade the extracellular matrix. Epidermal growth factor, like other factors, was not able to induce invasion.

We finally verified the ability of HGF to induce branching morphogenesis in BME-UV cells. Tubular branching is a complex morphogenic process that requires tight coordination of cell growth, polarity, and movement. Cells of different origin, when treated with $\mathrm{HGF}$, form lumen structures and branched tubules (Tsarfaty et al., 1992). The morphogenetic responses induced by the HGF/Met couple in these cells in-vitro are unique and cannot be elicited by other receptor tyrosine kinases (Sachs et al., 1996). Moreover in the mammary gland, elevated expression of endogenous Met and HGF correlates with stages of active tubulogenesis, their expression being high through early pregnancy but virtually absent during late pregnancy and lactation when alveologenesis and gland differentiation take place (Niranjan et al., 1995; Yang et al., 1995). Only HGF treatment, although at a low degree, promoted the formation of branched tubules in BME-UV cells, whereas EGF did not induce tubule formation. Given that the number of tubules that developed was very limited, we are now trying to subclone BME-UV cell line to obtain a single clone able to respond to HGF with a high tubulogenic capacity.

The fact that HGF, but not EGF, can induce multiple biological responses in this cell line is intriguing. A possible explanation for this phenomenon is that whereas Erk activity is sustained in response to HGF, EGF-stimulated Erk activity is transient (Maroun et al., 2000). Our data indicate that after HGF treatment, Erk phosphorylation persists for only 30 to $45 \mathrm{~min}$, but it is possible that longer incubation times with $\mathrm{HGF}$ (>60 min) may keep Erk activated. Another possible explanation is that HGF treatment activates some downstream effectors that EGF or other factors cannot elicit. The FAK kinase, for example, has been recently shown to directly interact with the HGF receptor and to be a critical determinant for Met-mediated cell motility and cell invasion (Chen and Chen, 2006). We are now addressing this possibility in our bovine cell model.

In conclusion, we tested whether the bovine mammary epithelial cell line BME-UV was responsive to HGF and determined which biological effects were induced by this cytokine. As a first step we confirmed that BME-UV cells express Met at the mRNA and the protein level. Subsequently, we demonstrated that HGF activates 2 fundamental signaling pathways, the Erk/MAPK pathway and the Akt pathway. Given that the activation of these pathways, and in particular MAPK, is responsible for proliferation, we established that HGF was able to induce proliferation in BME-UV cells. We also established the ability of HGF on BMEUV cell line to induce scatter, degrade the extracellular matrix, and migrate. Finally we demonstrated that HGF is able to induce, although to a low degree, the formation of complex tubular structure, reminiscent of the mammary gland ducts, on BME-UV cells when resuspended in a 3-dimensional collagen matrix. The effects described in this work show how HGF and its receptor Met promoted proliferation on one hand and complex motogenic and morphogenic cellular responses on the other. These effects establish a significant role of HGF and Met in the physiology of the bovine mammary gland.

\section{ACKNOWLEDGMENTS}

This work was supported by grants from Regione Piemonte A122, COFIN 2005, and Compagnia di San Paolo.

\section{REFERENCES}

Bardelli, A., P. Longati, D. Albero, S. Goruppi, C. Schneider, C. Ponzetto, and P. M. Comoglio. 1996. HGF receptor associates with 
the anti-apoptotic protein BAG-1 and prevents cell death. EMBO J. 15:6205-6212.

Birchmeier, C., and E. Gherardi. 1998. Developmental roles of HGF/ $\mathrm{SF}$ and its receptor, the c-Met tyrosine kinase. Trends Cell Biol. 8:404-410.

Bottaro, D. P., J. S. Rubin, D. L. Faletto, A. M. Chan, T. E. Kmiecik, G. F. Vande Woude, and S. A. Aaronson. 1991. Identification of the hepatocyte growth factor receptor as the c-met proto-oncogene product. Science 251:802-804.

Brinkmann, V., H. Foroutan, M. Sachs, K. M. Weidner, and W. Birchmeier. 1995. Hepatocyte growth factor/scatter factor induces a variety of tissue-specific morphogenic programs in epithelial cells. J. Cell Biol. 131:1573-1586.

Bussolino, F., M. F. Di Renzo, M. Ziche, E. Bocchietto, M. Olivero, L. Naldini, G. Gaudino, L. Tamagnone, A. Coffer, and P. M. Comoglio. 1992. Hepatocyte growth factor is a potent angiogenic factor which stimulates endothelial cell motility and growth. J. Cell Biol. 119:629-641.

Chen, S. Y., and H. C. Chen. 2006. Direct interaction of focal adhesion kinase (FAK) with Met is required for FAK to promote hepatocyte growth factor-induced cell invasion. Mol. Cell. Biol. 26:5155-5167.

Cooper, C. S., M. Park, D. G. Blair, M. A. Tainsky, K. Huebner, C. M. Croce, and G. F. Vande Woude. 1984. Molecular cloning of a new transforming gene from a chemically transformed human cell line. Nature 311:29-33.

Ellis, S., and A. V. Capuco. 2002. Cell proliferation in bovine mammary epithelium: Identification of the primary proliferative cell population. Tissue Cell 34:155-163.

Gherardi, E., and M. Stoker. 1990. Hepatocytes and scatter factor. Nature 346:228.

Hecht, M., J. H. Schulte, A. Eggert, J. Wilting, and L. Schweigerer. 2005. The neurotrophin receptor TrkB cooperates with c-Met in enhancing neuroblastoma invasiveness. Carcinogenesis 26:2105-2115.

Kadono, Y., K. Shibahara, M. Namiki, Y. Watanabe, M. Seiki, and H. Sato. 1998. Membrane type 1-matrix metalloproteinase is involved in the formation of hepatocyte growth factor/scatter factorinduced branching tubules in Madin-Darby canine kidney epithelial cells. Biochem. Biophys. Res. Commun. 251:681-687.

Khwaja, A., K. Lehmann, B. M. Marte, and J. Downward. 1998. Phosphoinositide 3-kinase induces scattering and tubulogenesis in epithelial cells through a novel pathway. J. Biol. Chem. 273:18793-18801.

Livak, K. J., and T. D. Schmittgen. 2001. Analysis of relative gene expression data using real-time quantitative PCR and the 2(Delta Delta C(T)) Method. Methods 25:402-408.

Maritano, D., P. Accornero, N. Bonifaci, and C. Ponzetto. 2000. Two mutations affecting conserved residues in the Met receptor operate via different mechanisms. Oncogene 19:1354-1361.

Maroun, C. R., M. A. Naujokas, M. Holgado-Madruga, A. J. Wong, and M. Park. 2000. The tyrosine phosphatase SHP-2 is required for sustained activation of extracellular signal-regulated kinase and epithelial morphogenesis downstream from the met receptor tyrosine kinase. Mol. Cell. Biol. 20:8513-8525.

Medico, E., A. M. Mongiovi, J. Huff, M. A. Jelinek, A. Follenzi, G. Gaudino, J. T. Parsons, and P. M. Comoglio. 1996. The tyrosine kinase receptors Ron and Sea control "scattering" and morphogenesis of liver progenitor cells in vitro. Mol. Biol. Cell 7:495-504.

Montesano, R., K. Matsumoto, T. Nakamura, and L. Orci. 1991. Identification of a fibroblast-derived epithelial morphogen as hepatocyte growth factor. Cell 67:901-908.
Nakamura, T., T. Nishizawa, M. Hagiya, T. Seki, M. Shimonishi, A. Sugimura, K. Tashiro, and S. Shimizu. 1989. Molecular cloning and expression of human hepatocyte growth factor. Nature 342:440-443.

Niranjan, B., L. Buluwela, J. Yant, N. Perusinghe, A. Atherton, D. Phippard, T. Dale, B. Gusterson, and T. Kamalati. 1995. HGF/ SF: A potent cytokine for mammary growth, morphogenesis and development. Development 121:2897-2908.

Potempa, S., and A. J. Ridley. 1998. Activation of both MAP kinase and phosphatidylinositide 3-kinase by Ras is required for hepatocyte growth factor/scatter factor-induced adherens junction disassembly. Mol. Biol. Cell 9:2185-2200.

Ridley, A. J., P. M. Comoglio, and A. Hall. 1995. Regulation of scatter factor/hepatocyte growth factor responses by Ras, Rac, and Rho in MDCK cells. Mol. Cell. Biol. 15:1110-1122.

Rosario, M., and W. Birchmeier. 2003. How to make tubes: Signaling by the Met receptor tyrosine kinase. Trends Cell Biol. 13:328-335.

Sachs, M., K. M. Weidner, V. Brinkmann, I. Walther, A. Obermeier, A. Ullrich, and W. Birchmeier. 1996. Motogenic and morphogenic activity of epithelial receptor tyrosine kinases. J. Cell Biol. 133:1095-1107.

Soriano, J. V., M. S. Pepper, T. Nakamura, L. Orci, and R. Montesano. 1995. Hepatocyte growth factor stimulates extensive development of branching duct-like structures by cloned mammary gland epithelial cells. J. Cell Sci. 108:413-430.

Stoker, M., E. Gherardi, M. Perryman, and J. Gray. 1987. Scatter factor is a fibroblast-derived modulator of epithelial cell mobility. Nature 327:239-242.

Taulli, R., P. Accornero, A. Follenzi, T. Mangano, A. Morotti, C. Scuoppo, P. E. Forni, F. Bersani, T. Crepaldi, R. Chiarle, L. Naldini, and C. Ponzetto. 2005. RNAi technology and lentiviral delivery as a powerful tool to suppress Tpr-Met-mediated tumorigenesis. Cancer Gene Ther. 12:456-463.

Tsarfaty, I., J. H. Resau, S. Rulong, I. Keydar, D. L. Faletto, and G. F. Vande Woude. 1992. The met proto-oncogene receptor and lumen formation. Science 257:1258-1261.

Vivanco, I., and C. L. Sawyers. 2002. The phosphatidylinositol 3Kinase AKT pathway in human cancer. Nat. Rev. Cancer 2:489-501.

Wasylyk, B., J. Hagman, and A. Gutierrez-Hartmann. 1998. Ets transcription factors: Nuclear effectors of the Ras-MAP-kinase signaling pathway. Trends Biochem. Sci. 23:213-216.

Yamaji, D., K. Kimura, A. Watanabe, Y. Kon, T. Iwanaga, M. M. Soliman, M. M. Ahmed, and M. Saito. 2006. Bovine hepatocyte growth factor and its receptor c-Met: cDNA cloning and expression analysis in the mammary gland. Domest. Anim. Endocrinol. 30:239-246.

Yang, Y., E. Spitzer, D. Meyer, M. Sachs, C. Niemann, G. Hartmann, K. M. Weidner, C. Birchmeier, and W. Birchmeier. 1995. Sequential requirement of hepatocyte growth factor and neuregulin in the morphogenesis and differentiation of the mammary gland. J. Cell Biol. 131:215-226.

Yant, J., L. Buluwela, B. Niranjan, B. Gusterson, and T. Kamalati. 1998. In vivo effects of hepatocyte growth factor/scatter factor on mouse mammary gland development. Exp. Cell Res. 241:476-481.

Zavizion, B., M. van Duffelen, W. Schaeffer, and I. Politis. 1996. Establishment and characterization of a bovine mammary epithelial cell line with unique properties. In Vitro Cell Dev. Biol. Anim 32:138-148. 